\title{
Liver Cirrhosis in a Patient
} with Sickle Cell Trait (Hb S $\beta^{+}$ Thalassemia) without Other Known Causes of Hepatic Disease

\author{
Luca Santi $^{\mathrm{a}}$ Giancarlo Montanari $^{\mathrm{a}}$ Sonia Berardi ${ }^{\mathrm{b}}$ \\ Corrado Patti $^{a}$ Marta Frigerio ${ }^{a}$ Claudia Sama ${ }^{a}$ \\ Paolo Caraceni ${ }^{\mathrm{a}}$ Mauro Bernardi ${ }^{\mathrm{a}}$
}

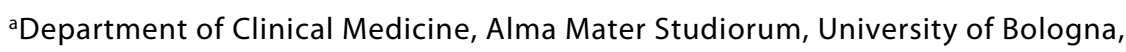

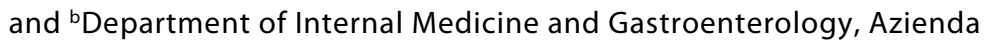
Ospedaliera-Universitaria, Policlinico S. Orsola-Malpighi, Bologna, Italy

\section{Key Words}

Liver cirrhosis · Sickle cell disease · Sickle cell trait · Iron overload

\begin{abstract}
Liver involvement in patients with sickle cell anemia/trait includes a wide range of alterations, from mild liver function test abnormalities to cirrhosis and acute liver failure. Approximately $15-30 \%$ of patients with sickle cell anemia present cirrhosis at autopsy. The pathogenesis of cirrhosis is usually related to chronic hepatitis $B$ or $C$ infection or to iron overload resulting from the many transfusions received by these patients in their lifetime. Thus, cirrhosis has been described almost exclusively in patients with sickle cell anemia, while only mild liver abnormalities have been associated with the sickle cell trait. In the present case study, we describe a young Mediterranean man carrying a sickle cell trait $\left(\mathrm{Hb} \mathrm{S} \beta^{+}\right.$thalassemia) who developed liver cirrhosis being negative for hepatitis $\mathrm{C}$ and $B$ viruses or for other causes of cirrhosis and not receiving chronic blood transfusions.
\end{abstract}

Sickle cell disease (SCD) is an inherited hematological disorder characterized by the presence of the variant hemoglobin $\mathrm{Hb} \mathrm{S}$ resulting from the substitution of thymine for adenine in the $\beta$-globin gene, thus encoding the aminoacid valin with glutamic acid in the sixth position of the $\beta$-chain gene [1]. SCD includes homozygous sickle cell anemia requiring life-long blood transfusions, and some heterozygote less severe clinical conditions defined as sickle cell trait [2]. 
Patients with sickle cell anemia/trait may suffer from a variety of hepatic alterations. The altered shape of red blood cells favors intravascular hemolysis and thus occlusion of the liver vascular bed, leading ultimately to tissue injury, which ranges from asymptomatic mild liver function test abnormalities to severe acute damage (acute sickle hepatic crisis). Furthermore, hemolysis induces deposition of bilirubin causing intrahepatic cholestasis and cholelithiasis [3]. Finally, approximately $15-30 \%$ of patients with sickle cell anemia present cirrhosis at autopsy [4-6]. Rather than a direct consequence of the hematological disease itself, the pathogenesis of cirrhosis is widely accepted to be related to chronic hepatitis $\mathrm{B}$ or $\mathrm{C}$ infection and iron overload as a result of hemolysis and multiple transfusions that these patients require in their lifetime [3]. Thus, it is not surprising that cirrhosis has been described almost exclusively in patients with sickle cell anemia, while only mild liver abnormalities have been associated with the sickle cell trait [3].

We describe the case of a young Mediterranean man carrying a sickle cell trait $\left(\mathrm{Hb} \mathrm{S} \beta^{+}\right.$ thalassemia) who developed liver cirrhosis being negative for hepatitis $\mathrm{C}(\mathrm{HCV})$ and hepatitis $\mathrm{B}(\mathrm{HBV})$ viruses or for other causes of cirrhosis and not receiving chronic blood transfusions.

\section{Case Report}

A 36-year-old Mediterranean man with cryptogenic liver cirrhosis and $\mathrm{Hb} S \beta^{+}$thalassemia came to our observation to be evaluated for liver transplantation. The diagnosis of sickle cell trait had been made in early childhood, while molecular analysis of the $\beta$-globin gene in 2001 had shown heterozygosis for the $\mathrm{Hb} \mathrm{S}$ mutation (sequence alteration $\mathrm{A}>\mathrm{T}$ ) and thalassemia $\beta+$ (mutation IVS-I.110, sequence alteration G>A). Hemoglobin electrophoresis revealed $\mathrm{Hb} S$ 71.6\%, $\mathrm{Hb} F 7.40 \%, \mathrm{Hb}$ A $15.9 \%$ and $\mathrm{Hb} \mathrm{A} 2$ $5.1 \%$. Asymptomatic liver test abnormalities consisting of mild elevation of serum transaminases and $\gamma$-glutamyltranspeptidase had been detected for the first time at the age of 30 years. A few years later, in 2003 , due to a progressive worsening of liver function tests and the appearance of hepatomegaly and scleral jaundice, the patient had undergone an extensive work-up, including liver biopsy, to determine the cause and stage of liver disease.

Biochemistry assessment showed elevation of serum transaminases (aspartate aminotransferase: $113 \mathrm{U} / \mathrm{l}$; alanine aminotransferase: $35 \mathrm{U} / \mathrm{l})$ and cholestatic enzymes ( $\gamma$-glutamyltranspeptidase: $206 \mathrm{U} / \mathrm{l}$; alkaline phosphatase: $251 \mathrm{U} / \mathrm{l}$ ), hyperbilirubinemia (total: $4.61 \mathrm{mg} / \mathrm{dl}$; conjugated bilirubin: $2.41 \mathrm{mg} / \mathrm{dl}$ ), and hypergammaglobulinemia. White blood count, platelets, coagulative tests, albumin, renal function, electrolytes and metabolic parameters were normal, serum ferritin was markedly elevated $(1,249 \mathrm{ng} / \mathrm{ml})$, but the genetic analyses for hereditary hemochromatosis did not unveil mutations for the HFE, transferrin receptor 2 and ferroportin genes. Hepatotropic viruses (HCV and HBV, cytomegalovirus, Epstein-Barr virus) tested negative. Anti-nuclear, anti-mitochondria, anti-LKM antibodies, and antineutrophil cytoplasmic antibodies were absent, while a low-titer aspecific positivity for the anti-smooth muscle antibody was found. Serum ceruloplasmin and $\alpha$-1-antripsin levels were within the normal range. The patient was abstinent for alcohol and his body mass index was normal. Liver histology documented cirrhosis with large fibrotic septa and regenerative nodules; sinusoids appeared dilated and engorged by red blood cells with an altered morphology; finally, Pearl staining revealed iron deposition in Kupffer cells and hepatocytes (second-degree siderosis). Liver ultrasound showed hepatomegaly with a nodular coarse and gallbladder stones. It is important to note that until 2003, when cirrhosis was diagnosed, the hemoglobin serum levels had remained stable approximately around $8 \mathrm{~g} / \mathrm{dl}$ and the patient had received a low number of blood transfusions in his entire life $(<10$ units of red packed blood cells).

The patient then started iron chelating therapy with desferrioxamine which was stopped two years later because of a significant reduction in serum ferritin $(419 \mathrm{ng} / \mathrm{ml})$; at that time the hepatic iron concentration was $223 \mu \mathrm{g} \mathrm{Fe} / \mathrm{g}$ liver (normal value $<400 \mu \mathrm{g} \mathrm{Fe} / \mathrm{g}$ liver) at the Super Quantum Interference Device (SQUID 5700 3-Channel, Tristan technologies Inc, San Diego, USA). Despite this, liver function tests progressively deteriorated and the patient was referred to our hospital at the end of 2006 to be evaluated for liver transplantation. At that time, laboratory test showed marked hyperbilirubinemia (total: $13.02 \mathrm{mg} / \mathrm{dl}$; conjugated bilirubin: $7.31 \mathrm{mg} / \mathrm{dl}$ ) and development of 
coagulopathy (INR: 1.54$)$ and hypoalbuminemia $(2.95 \mathrm{~g} / \mathrm{dl})$. Serum ferritin was close to the upper normal limit ( $316 \mathrm{ng} / \mathrm{ml}$ ). The patient was in class B9 of Child-Pugh (mild ascites and encephalopathy), while MELD score was 21. Upper endoscopy showed medium-sized esophageal varices and portal hypertensive gastropathy. No cardiac, renal or respiratory diseases were found and the patient was accepted in the waiting list for liver transplantation.

Subsequently, his clinical conditions progressively deteriorated with a sudden exacerbation of the hematological disease. Indeed, the patient presented chronic hemolysis requiring blood transfusions every 2-3 weeks to maintain a hemoglobin level higher than $8 \mathrm{~g} / \mathrm{dl}$, while serum ferritin increased up to $8,891 \mathrm{ng} / \mathrm{ml}$ and iron-chelating therapy was restarted in June 2008. Unfortunately, the patient died in August 2008 from septic shock before being transplanted.

\section{Discussion}

Autopsy series indicate a $16-29 \%$ prevalence of cirrhosis in sickle cell anemia patients [4-6]. In almost all cases, cirrhosis develops in the presence of homozygous sickle cell anemia as a consequence of chronic hepatitis B or C infection or iron overload due to the multiple blood transfusions that these patients require in their lifetime [3]. In contrast, patients with microdrepanocytosis rarely show hepatic involvement, the severity of which appears to be mild, particularly in the white Mediterranean population [7]. An Italian study in patients with sickle cell anemia, sickle cell trait, and sickle $\beta$ thalassemia documented that only 2 of 142 patients had significantly abnormal liver function tests, with marginal abnormalities being seen in the remainder [8]; moreover, both patients were positive for HBsAg and HCV antibody, so that their liver disease could be related to the viral infection rather than to the hematological disorder [8].

The major finding in our case is represented by the possibility that a patient carrying a sickle cell trait $\left(\mathrm{Hb} \mathrm{S} \beta^{+}\right.$thalassemia) and not receiving chronic blood transfusions can develop liver cirrhosis being negative for HCV and HBV or for other causes of cirrhosis. Up to now, only very rare cases of unexplained cirrhosis have been diagnosed in patients with microdrepanocytosis. Namely, Lerut et al. [9] reported a case of a Sicilian woman with $S \beta^{+}$thalassemia with cryptogenic cirrhosis who developed allograft dysfunction due to intrahepatic sickling after liver transplantation; however, the positivity for anti-nuclear antibodies (1/160) may suggest the presence of a concomitant autoimmune hepatitis as a possible cause of cryptogenic cirrhosis. A second case of cryptogenic cirrhosis has been recently described in a Ghanaian man with $S \beta^{+}$thalassemia $[10,11]$. Interestingly, as in our case, this patient was asymptomatic for liver disease until adulthood, when he presented features of subacute liver failure and histological cirrhosis with superimposed cholestasis and necrosis.

It remains unclear why a patient with an apparently benign genotype of SCD can develop cirrhosis in absence of any other etiological cause. Our patient experienced the typical manifestations of liver failure and portal hypertension, although jaundice and mixed hyperbilirubinemia represented a prominent feature even when cirrhosis was well-compensated. Moreover, the liver biopsy, beside the histological cirrhosis, showed a second degree of siderosis and evidence of sickling in the liver sinusoids. Unfortunately, the amount of hepatic iron was not quantified before iron depletion therapy. Thus, it can be hypothesized that multiple concomitant pathophysiological events, represented by cholestasis, sickling-related ischemia, and liver iron deposition, may have contributed to the development of chronic liver disease and, ultimately, cirrhosis. With regard to iron deposition, although the major mutations related to genetic hemochromatosis have been searched and ruled out, we cannot exclude with certainty the presence of other rare gene defects of iron metabolism [12]. 
An intriguing observation emerging from our case study is related to the onset of the clinical manifestations and complications of cirrhosis temporally related to a sudden deterioration of the hematological disease. In fact, contrary to what occurred prior to 2007, when the hemoglobin levels remained quite stable, the patient presented chronic hemolysis requiring blood transfusions every $2-3$ weeks and iron-chelating therapy in the last year.

In conclusion, this case report documents the possibility that patients with sickle cell trait $\left(\mathrm{Hb} \mathrm{S} \beta^{+}\right.$thalassemia) can develop cirrhosis even in the absence of other manifest causes of chronic liver disease. This observation also suggests that patients with heterozygote conditions should be followed to exclude significant hepatic involvement. 


\section{References}

1 Traina F, Jorge SG, Yamanaka A, de Meirelles LR, Costa FF, Saad ST: Chronic liver abnormalities in sickle cell disease: a clinicopathological study in 70 living patients. Acta Haematol 2007;118:129-135.

-2 Serjeant GR: Sickle-cell disease. Lancet 1997;350:725-730.

3 Banerjee S, Owen C, Chopra S: Sickle cell hepatopathy. Hepatology 2001;33:10211028.

-4 Bauer TW, Moore GW, Hutchins GM: The liver in sickle cell disease. A clinicopathologic study of 70 patients. Am J Med 1980;69:833-837.

5 Song YS: Hepatic lesions in sickle cell anemia. Am J Pathol 1957;33:331-334.

6 Green TW, Conley CL, Berthrong M: The liver in sickle cell anemia. Bull J Hopkins Hosp 1953;92:99-122.

7 Schiliro G, Samperi P, Consalvo C, Gangarossa S, Testa R, Miraglia V, Lo Nigro L: Clinical, hematological, and molecular features in Sicilians with sickle cell disease. Hemoglobin 1992;16:469-480.

8 Samperi P, Consalvo C, Romano V, Gelardi S, Di Bella D, Schiliro G: Liver involvement in white patients with sickle-cell disease. Arch Pediatr Adolesc Med 1996;150:1177-1180.

-9 Lerut JP, Clayes N, Laterre PF, Lavenne-Pardonge E, Ciccarelli O, Cavallaro S, Palazzo U, Renda D, Rigano P, Maggio A: Hepatic sickling: an unusual case of liver allograft dysfunction. Transplantation 1999;67:65-68.

$\checkmark 10$ Cross TJS, Berry PA, Akbar N, Wendon J, Thein SL, Harrison PM: Sickle liver disease. An unusual presentation in a compound heterozygote for $\mathrm{HbS}$ and a novel B-thalassemia mutation. Am J Hematol 2007;82:852-854.

11 Berry PA, Cross TJS, Thein SL, Portmann BC, Wendon JA, Karani JB, Heneghan MA, Bomford A: Hepatic dysfunction in sickle cell disease: a new system of classification based on global assesment. Clin Gastroenterol Hepatol 2007;5:14691476.

12 Adams PC, Barton JC: Haemochromatosis. Lancet 2007;370:1855-1860. 